\title{
Hypothesis: excessive bronchoconstriction in asthma
}

\author{
A.M. Bramley, R.J. Thomson, C.R. Roberts, R.R. Schellenberg
}

Hypothesis: excessive bronchoconstriction in asthma is due to decreased airway elastance. A.M. Bramley, R.J. Thomson, C.R. Roberts, R.R. Schellenberg. CERS Journals Ltd 1994. ABSTRACT: Based on the strikingly different mechanical properties of airway smooth muscle preparations of different species, we hypothesized that a decrease in the elastance of nonmuscle elements within airway walls of asthmatics reduces the load limiting smooth muscle shortening, thereby allowing excessive smooth muscle shortening and bronchoconstriction.

Full thickness, circumferentially cut, lobar bronchial preparations were obtained from one asthmatic and six nonasthmatic lobectomy subjects.

Passive tension of the asthmatic preparation was less than that for any nonasthmatic preparation at all lengths below that for optimal force generation (Lmax). Maximal isometric force generation was greater in the asthmatic specimen $(2.32 \mathrm{~g})$ than in the nonasthmatic specimens $(0.90 \pm 0.15 \mathrm{~g})$, with stress threefold higher for the asthmatic tissue. Isotonic shortening of the asthmatic preparation was strikingly greater at starting lengths less than or equal to Lmax, with maximal fractional shortening being $31 \%$ versus $11 \pm 2 \%$ for nonasthmatic preparations. Morphometric analysis revealed no differences in cross-sectional areas of smooth muscle for asthmatic versus nonasthmatic preparations.

We conclude that the reduced tissue elastance may account for the greater muscle shortening by placing a lesser load upon the smooth muscle. Airway inflammation in asthma may alter connective tissue matrix elements within airway walls leading to this decreased elastance and excessive smooth muscle shortening.

Eur Respir J., 1994, 7, 337-341.
UBC Pulmonary Research Laboratory, St Paul's Hospital, Vancouver, BC, Canada.

Correspondence: R.R. Schellenberg UBC Pulmonary Research Laboratory St Paul's Hospital

1081 Burrard Street

Vancouver

BC V6Z 1 Y6

Canada

Keywords: Airway smooth muscle asthma

bronchoconstriction

muscle shortening

Received: March 301993

Accepted November 231993

Supported by the British Columbia Lung Association and the Respiratory Health Network of Centres of Excellence. AMB is the recipient of a Canadian Lung Association Fellowship. CRR is the recipient of a Medical Research Council/British Columbia Lung Association Scholarship.

\section{Hypothesis}

Decreased elastance of asthmatic airway tissue allows exaggerated smooth muscle shortening.

\section{Rationale}

The ability of airway smooth muscle preparations to shorten appears to be inversely related to the amount of extracellular matrix elements present within the preparation utilized. We have previously demonstrated that human mainstem bronchi shorten minimally (maximal fractional shortening 25\%) [1] when compared with comparable preparations from the dog or pig (maximal fractional shortening 70-80\%) [2, 3]. Porcine trachealis tissue contains threefold greater amounts of muscle per crosssectional area than does that of humans. It has correspondingly less extracellular matrix between muscle fibres as well as surrounding the muscle. These porcine preparations demonstrate low elastance when compared to the human counterparts. Thus, passive tension at the length for optimal force generation (Lmax) is 5\% [2] of the maximal isometric force produced for porcine airway versus $60 \%$ for human [1]. These observations suggest that the limited amount of shortening of human airway preparations may be due to the greater tissue elastance, which places a load on the smooth muscle, limiting shortening. The fact that preparations with much greater muscle and less extracellular matrix have substantially less elastance suggests that elements within muscle cells themselves provide minimal resistance to shortening, when compared with elements extrinsic to the muscle cells. Compatible with this assumption is the very low stiffness of isolated smooth muscle cells [4], which demonstrate high fractional shortening [5].

These observations raise the possibility that smooth muscle within asthmatic airways could shorten excessively, simply due to a decrease in the load provided by extracellular matrix elements, without the requirement for altered properties of the muscle itself. This concept is depicted schematically in figure 1. Increased shortening would be magnified if there was a greater amount of smooth muscle within the airway, as this would have less elastance than nonmuscle tissue. Although the mechanisms whereby such changes in airway elastance might occur in asthma are speculative, the mechanical consequences can be evaluated. 
Airway smooth muscle shortening

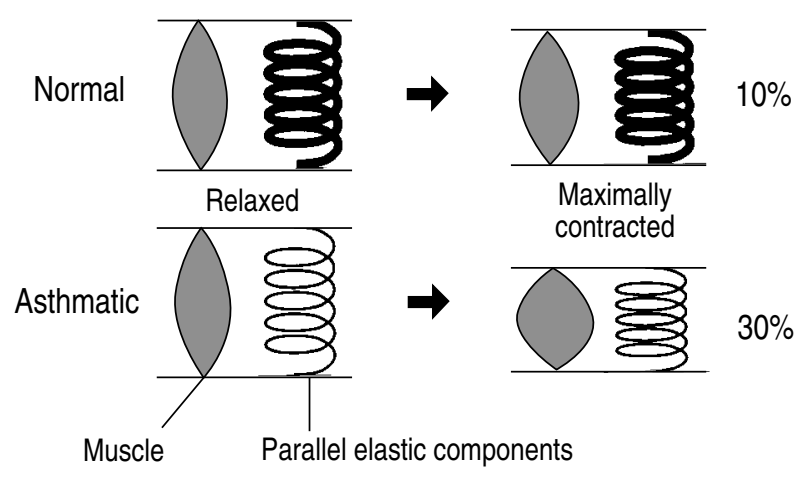

Fig. 1. - Schematic diagram illustrating how a decrease in stiffness of parallel elastic components (depicted by the springs) within airway tissue allows greater smooth muscle shortening. Percentage maximal fractional shortening values are those obtained for nonasthmatic $(10 \%)$ versus asthmatic $(30 \%)$ bronchial preparations.

\section{Experimental evidence}

Bronchial tissues from one asthmatic and six nonasthmatic patients undergoing lobectomy for lung carcinoma, were obtained within 30 min of surgery and placed in KrebsHenseleit solution. A $1 \times 2 \times 5 \mathrm{~mm}$ full-thickness tissue strip, perpendicular to the longitudinal axis, was cut from the tumour-free bronchus and placed in an oxygenated tissue bath as described previously [1]. Measurements of muscle mechanics were performed using a special device for determining both isometric and isotonic responses of smooth muscle [2]. Length measurements were made using an optical micrometer (accurate to $0.001 \mathrm{~cm}$ ) at increasing preloads between $0-2.5 \mathrm{~g}$, and both active isometric and isotonic responses to electrical field stimulation (EFS) were obtained at each preload. The passive lengthtension curve was continued until the length equalled approximately $110 \%$ of the length at which maximum force generation was obtained (Lmax). At the end of each experiment, contractile responses to acetylcholine (ACh) $10^{-4} \mathrm{M}$ were obtained. For data analysis, muscle lengths were standardized by Lmax, the length at which maximum active tension (Pmax) was generated. Fractional shortening was calculated as percentage change in length/initial length at each preload. Morphometry was performed according to methods described previously [1].

The asthmatic subject, who also underwent lobectomy for carcinoma, was a 65 year old female nonsmoker with a long-standing history of mild asthma controlled with an inhaled $\beta_{2}$-agonist. She had never received inhaled corticosteroids and had not received oral corticosteroids within the six months prior to surgery. Forced expiratory volume in one second/forced vital capacity $\left(\mathrm{FEV}_{1} / \mathrm{FVC}\right)$ was $71 \%$, with $\mathrm{FEV}_{1} 91 \%$ predicted and forced midexpiratory flow $\left(\mathrm{FEF}_{25-75}\right) 58 \%$ predicted. Total lung capacity (TLC) and functional residual capacity (FRC) were normal. Allergy testing and bronchoprovocation were not performed. Histological evaluation of airways revealed characteristic features of asthma, including epithelial

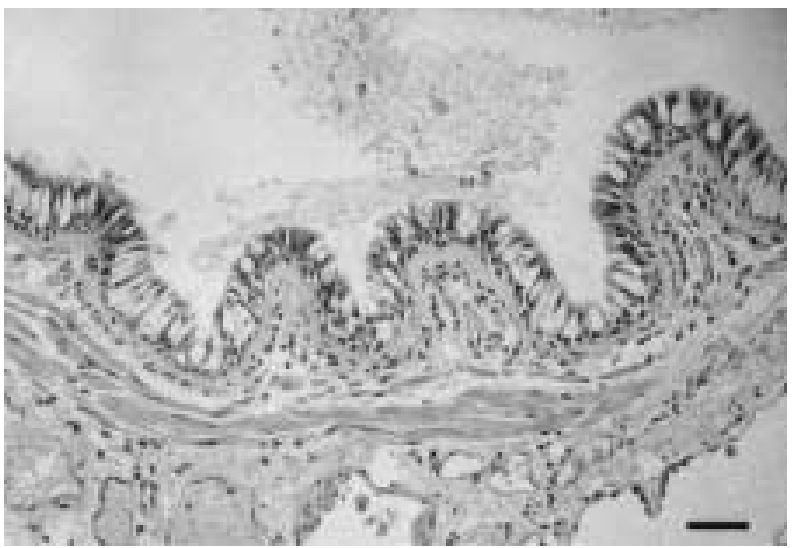

Fig. 2. - Histological section of airway from an asthmatic subject. Characteristic features of asthma include: epithelial desquamation and intraluminal mucus secretion $(\mathrm{M})$; goblet cell metaplasia $(\mathrm{G})$; collagen deposition below basement membrane $(\mathrm{C})$; prominent smooth muscle (S); mucosal and submucosal inflammation. (magnification $\times 260$. Scale bar $=50 \mu \mathrm{m})$.

desquamation, intraluminal mucus, goblet cell hyperplasia, collagen deposition below the basement membrane, mucosal and submucosal inflammation, and prominent smooth muscle (fig. 2).

\section{Passivellength tension relationships}

The lobar bronchus from the asthmatic subject developed less passive tension with stretching than did the nonasthmatic lobar smooth muscle tissues. At Lmax, passive tension of the asthmatic smooth muscle was $75 \%$ of Pmax, whereas the nonasthmatic lobar tissues averaged 180\% Pmax $(n=6)$ (fig. 3). Values of absolute tension were comparable for the asthmatic and nonasthmatic lobar tissues at Lmax, but passive tension of the asthmatic tissue was significantly less at all lengths evaluated below Lmax, with none of the values falling within the range of those for the nonasthmatic tissues.

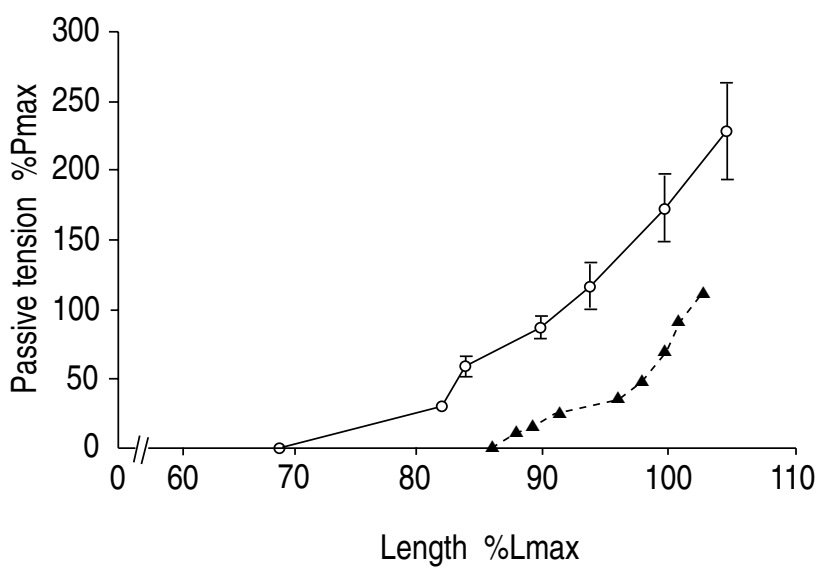

Fig. 3. - Passive length-tension characteristics of human nonasthmatic lobar bronchi $(n=6)(-\infty-)$ compared with an asthmatic lobar bronchus (-- - ). Passive tension expressed as percentage maximum isometric force generated (\% Pmax) and length as percentage length at which maximal isometric forced was obtained (\% Lmax). Data for nonasthmatic tissues are presented as mean \pm SEM. 
Table 1. - Parameters for asthmatic and nonasthmatic lobar bronchial smooth muscle

\begin{tabular}{|c|c|c|}
\hline & Asthmatic & Nonasthmatic \\
\hline Maximal fractional shortening $\%$ & 31 & $11 \pm 2$ \\
\hline Total tissue area $\mathrm{mm}^{2}$ & 11.6 & $7.6 \pm 1.5$ \\
\hline Muscle area $\mathrm{mm}^{2}$ & 0.24 & $0.28 \pm 0.06$ \\
\hline$\%$ smooth muscle & 2.0 & $4.0 \pm 0.9$ \\
\hline Force generation $\mathrm{g}$ & 2.32 & $0.90 \pm 0.15$ \\
\hline Stress $\mathrm{kg} \cdot \mathrm{cm}^{-2}$ & 0.98 & $0.30 \pm 0.05$ \\
\hline
\end{tabular}

Data are presented as mean \pm SEM $(n=6)$ for nonasthmatic bronchi.

\section{Isometric force}

Maximal isometric force generation was significantly increased $(2.32 \mathrm{~g})$ in the asthmatic tissue compared with nonasthmatic tissues $(0.9 \pm 0.15 \mathrm{~g})$ (table 1$)$. This enhanced response was observed at all starting lengths. Force per cross-sectional area (stress) was markedly greater for the asthmatic tissue $\left(0.98 \mathrm{~kg} \cdot \mathrm{cm}^{-2}\right)$ versus nonasthmatic tissues $\left(0.3 \pm 0.05 \mathrm{~kg} \cdot \mathrm{cm}^{-2}\right)$.

No changes in characteristics of the responses to EFS were noted. The asthmatic tissue demonstrated equivalent nonadrenergic, noncholinergic inhibition compared to the nonasthmatic preparations.

\section{Isotonic shortening}

Maximal fractional shortening occurred at similar starting lengths ( $\sim 80 \%$ Lmax) in both the asthmatic and nonasthmatic lobar bronchial tissues (fig. 4). However, maximal fractional shortening was significantly greater in the asthmatic tissue $(31 \%)$ compared with nonasthmatic tissues $(11 \pm 2 \%)$. Shortening was greater for the asthmatic tissue at all starting lengths below Lmax, and was 16\% compared with $6 \%$ for nonasthmatic tissues at Lmax. Maximum shortening to exogenously administered ACh was 33\% for the asthmatic tissue versus $14 \pm 2 \%$ for the nonasthmatic.

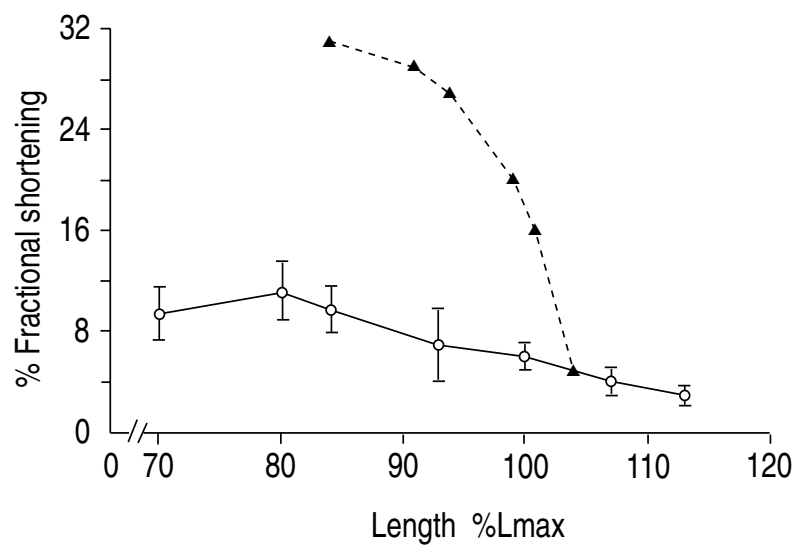

Fig. 4. - Fractional shortening of human asthmatic lobar bronchi $\left(-\mathbf{\Lambda}_{-}\right)$and nonasthmatic lobar bronchi $(n=6)\left(\bigcirc_{-}\right)$at various starting lengths during isotonic preloaded contractions. Data are presented as mean \pm SEM. \%Lmax: percentage at which maximal isometric force was obtained.

\section{Morphometrics}

Results of the morphometric evaluation of the crosssectional areas of muscle and total tissue areas showed no difference between the amount of smooth muscle of the asthmatic compared with the nonasthmatics (table $1)$.

When all extracellular matrix was subtracted, the smooth muscle represented only $2 \%$ of the total tissue area.

\section{Discussion}

These results provide the first direct evidence that asthmatic airway smooth muscle shortens more than that from nonasthmatic subjects. Although these results are observations from a single asthmatic airway preparation, we feel the magnitude of the differences compared with all other lobar preparations studied is striking. Lobar preparations demonstrate significantly less shortening and higher passive tension than mainstem preparations. In our 27 lobar bronchial preparations so far studied using comparable experimental protocols, the highest value for the maximum fractional shortening was $22 \%$, with the mean value $=11 \pm 0.9 \%$. Therefore, shortening in the asthmatic tissue $(31 \%)$ was threefold greater than the mean for nonasthmatic tissues.

We found no difference in the value of smooth muscle area from asthmatic and nonasthmatic lobar bronchi, suggesting that the increase in force generation was not due to an increased amount of smooth muscle, which surprised us. Interestingly, our pathologist reported increased smooth muscle as a component of the histological evaluation in our asthmatic subject, whereas careful morphometric analysis showed this to be an inaccurate qualitative impression.

Previous studies have demonstrated increased amounts of smooth muscle in asthmatic airways using morphometric measurements [6-13]. However, these studies may have overestimated the amount of smooth muscle, due to techniques which limit the ability to exclude extracellular matrix within the measured muscle bundles. All studies utilized transverse airway sections which provide circumferential views of the smooth muscle. A qualitative comparison of circumferential versus cross-sectional views of muscle bundles reveals that differentiation of extracellular matrix within muscle bundles is much more difficult with circumferentially sectioned muscle bundles. Previous studies also utilized paraffin-embedding and, consequently, thick tissue sections, which further obscures the smooth muscle/extracellular matrix boundaries. Finally, these studies utilized low magnifications for measuring muscle bundle areas. This was probably done to keep entire circumferential muscle bundles in the field of view (i.e. the whole airway), which would result in poor resolving power with respect to the extracellular matrix elements within the bundles, which were probably included in the muscle area measurements. In our measurements, the majority of the extracellular matrix was subtracted from the total muscle bundle area when quantifying amounts of smooth muscle. It is clear that our technique provides 
a more critical look at the amount of smooth muscle in airway tissue, and we would suggest that these methods be used in future studies.

It is probable that both parallel elastic elements within the airway wall and series elastic elements extrinsic to the muscle limit muscle shortening and, thus, bronchoconstriction in normal subjects, which is evidenced by the plateau of the bronchoconstrictor agonist dose-response curve [14]. The excessive bronchoconstriction noted in asthma has been suggested to reflect a loss of normal elements limiting airway narrowing [15]. Other investigators have suggested that excessive bronchoconstriction observed in asthma could be explained on the basis of the mechanical effects of thickened walls, without a need for increased muscle shortening $[16,17]$. Due to the limited shortening of nonasthmatic human airway smooth muscle [1], this factor alone cannot account for the excessive bronchoconstriction noted in asthma. However, if asthmatic airway muscle shortening is increased threefold or more, large changes in airway resistance would occur, which would be further accentuated by thickened airway walls. The increased isometric force noted with the asthmatic preparation was inexplicable on the basis of increased muscle. This could be due to enhanced contractile properties of smooth muscle intracellular events, but might also be explained by a decrease in constraining matrix elements allowing a more parallel alignment of tangential muscle fibres to the vector of the force transducer.

The mechanisms causing decreased airway tissue elastance and increased muscle shortening are unknown. Many different inflammatory mediators have been implicated in asthma, but how they might bring about changes in smooth muscle or decrease the load on the muscle remains to be determined. We would suggest that the release of protease enzymes from infiltrating inflammatory cells or resident cells could degrade extracellular matrix elements. Elastases or collagenases have been shown to be secreted by neutrophils and macrophages [18-20]. The cytokines interleukin-1 (IL-1) and tumour necrosis factor- $\alpha(\mathrm{TNF}-\alpha)$ have been shown to release collagenase from neutrophils [21, 22], and TNF- $\alpha$ has been measured from alveolar macrophages following bronchial allergic challenge of subjects exhibiting a late asthmatic response $[23,24]$. This hypothesis is supported by our recent preliminary findings that incubation of human bronchial preparations with collagenase in vitro decreases the tissue elastance and increases smooth muscle shortening [25]. Alterations in subepithelial elastin, as demonstrated by others [26], might also decrease the load limiting airway smooth muscle shortening.

To summarize, we raise the hypothesis that one of the most important determinants of increased smooth muscle shortening is a decreased load on the smooth muscle. Although the specific mechanism(s) by which such changes occur in asthma remain to be defined, our results showing increased shortening and decreased airway elastance of bronchial tissue suggest that a decrease in the load provided by extracellular matrix components may be a consequence of airway inflammation in asthma. Such altered smooth muscle mechanical properties could account for airway hyperresponsiveness.

\section{References}

1. Ishida K, Paré PD, Hards J, Schellenberg RR. Mechanical properties of human bronchial smooth muscle in vitro. J Appl Physiol 1992; 73: 1481-1485.

2. Ishida K, Paré, PD, Blogg T, Schellenberg RR. Effects of elastic loading on porcine trachealis smooth muscle mechanics. J Appl Physiol 1990; 69(3): 1033-1039.

3. Okazawa M, Ishida K, Road J, Schellenberg RR, Paré $\mathrm{PD}$. In vivo and in vitro correlation of trachealis muscle contraction in dogs. J Appl Physiol 1992; 73(4) 14861493.

4. Fay FS. Isometric contractile properties of single isolated smooth muscle cells. Nature 1977; 265: 553-556.

5. Itoh T, Ikebe M, Kargacin GJ, Hartshorne DJ, Kemp BE, Fay FS. Effects of modulators of myosin light-chain kinase activity in single smooth muscle cells. Nature 1989; 338: 164-167.

6. Dunnill MS. The pathology of asthma, with special reference to changes in the bronchial mucosa. J Clin Pathol 1960; 13: 27-33.

7. Dunnill MS, Massarella GR, Anderson JA. A comparison of the quantitative anatomy of the bronchi in normal subjects, in status asthmaticus, in chronic bronchitis and in emphysema. Thorax 1969; 24: 176-179.

8. Ebina M, Yaegashi H, Chiba R, Takahashi T, Motomiya M, Tanemura M. Hyperreactive site in the airway tree of asthmatic patients revealed by thickening of bronchial muscles. A morphometric study. Am Rev Respir Dis 1990; 141: 1327-1332.

9. Heard BE, Hossain S. Hyperplasia of bronchial muscle in asthma. J Pathol 1973; 110: 319-331.

10. Kuwano K, Bosken CH, Paré PD, Bai TR, Wiggs BR, Hogg JC. Small airways dimensions in asthma and chronic obstructive pulmonary disease. Am Rev Respir Dis 1993; 1220-1225.

11. Jeffery PK. Morphology of the airway wall in asthma and in chronic obstructive pulmonary disease. 1. Morphometry. Am Rev Respir Dis 1991; 143: 1152-1158.

12. Saetta M, Di Stefano A, Rosina C, Thiene G, Fabbri LM. Quantitative structural analysis of peripheral airways and arteries in sudden fatal asthma. Am Rev Respir Dis 1991; 143: $138-143$.

13. Carroll N, Elliot J, Morton A, James A. The structure of large and small airways in nonfatal and fatal asthma. Am Rev Respir Dis 1993; 147: 405-410.

14. Woolcock AJ, Salome CM, Yan K. The shape of the dose-response curve to histamine in asthmatic and normal subjects. Am Rev Respir Dis 1984; 130: 71-75.

15. Macklem PT. Bronchial hyperresponsiveness. Chest 1985; 87: 158S-159S.

16. Moreno RH, Hogg JC, Paré PD. Mechanics of airway narrowing. Am Rev Respir Dis 1986; 136: 11711180.

17. James AL, Paré PD, Hogg JC. The mechanics of airway narrowing in asthma. Am Rev Respir Dis 1989; 139: 242-246.

18. Murphy G, Bretz U, Bagglioni M, Reynolds JJ. The latent collagenase and gelatinase of human polymorphonucleocytes. Biochem J 1980; 192: 517-525.

19. Hirose H, Patterson C, Pourmotabbed T, Mainard CL, Hasty KA. Structure-function relationship of human neutrophil collagenase: identification of regions responsible for substrate specificity and general proteinase activity. Proc Natl Acad Sci USA 1993; 90: 2569-2573.

20. Welgus HG, Cambell EJ, Bar-shavit Z, Senior RM, Teitelbaum SK. Human alveolar macrophages produce 
a fibroblast-like collagenase and collagenase inhibitor. $J$ Clin Invest 1985; 76: 219-224.

21. Saklatvala J, Pilsworth LM, Sarsfield SJ, Gavrilovic J, Heath JK. Pig catabolin is a form of interleukin-1. Cartilage and bone resorb, fibroblasts make prostaglandin and collagenase, and thymocyte proliferation is augmented in response to one protein. Biochem J 1984; 224: 461-466.

22. Duncan MR, Burman B. Differential regulation of collagen, glycosaminoglycan, fibronectin, and collagenase activity production in cultured human adult dermal fibroblasts by interleukin- $1 \alpha$ and $\beta$ and tumour necrosis factor- $\alpha$ and $\beta$. J Invest Dermatol 1989; 92: 699-706.

23. Gosset $\mathrm{P}$, Tsicopoulos A, Wallaert B, et al. Increased secretion of tumor necrosis factor- $\alpha$ and interleukin- 6 by alveolar macrophages consecutively to the late asthmatic reaction after bronchial allergen challenge. J Allergy Clin Immunol 1991; 88: 561-571.

24. Gosset P, Tsicopoulas A, Wallaert B, Vannimenus C, Capron A, Tonnel AB. Tumor necrosis factor-alpha and interleukin-6 production by human mononuclear phagocytes from allergic asthmatics after IgE-dependent stimulation. Am Rev Respir Dis 1992; 146: 768-774.

25. Bramley AM, Roberts CR, Schellenberg RR. Increased contractility of human bronchial smooth muscle after collagenase treatment. Am Rev Respir Dis 1993; A844.

26. Bousquet J, Chanez P, Lacoste JY, et al. Asthma: a disease remodelling the airways. Allergy 1992; 47: 3-11. 